\title{
Utilization of an Application in Dizziness Treatment: Pilot Study
}

\author{
Perin Sousa $\mathrm{DHA}^{1}$, Sousa $\mathrm{MGC}^{2 *}$, Silva Carneiro $\mathrm{JD}^{3}$, Maia $\mathrm{FA}^{3}$, Matos $\mathbf{R}^{3}$, \\ Boratto $\mathrm{M}^{4}$ and Alves $\mathrm{L}^{5}$ \\ ${ }^{1}$ Graduate in Audiology, Faculdade IDE, Brazil \\ ${ }^{2}$ Post-Doctorate in Health Gamified Digital Platforms, Federal University of Bahia, Brazil \\ ${ }^{3}$ Space Rocket, State University of Bahia, Brazil \\ ${ }^{4}$ Doctorate in Informatics, Polytechnic University of Valencia, Spain \\ ${ }^{5}$ Post-Doctorate in Digital Games and Learning, University of Turim, Italy
}

Pilot Study

Volume 6 Issue 1

Received Date: February 25, 2021

Published Date: March 11, 2021

DOI: $10.23880 /$ ooaj-16000208

*Corresponding author: Maria da Glória Canto de Sousa, Post-Doctorate in Health Gamified Digital Platforms, Federal University of Bahia, Salvador, Brazil, Tel: +5571988690903; Email: gcanto@uneb.br

\section{Abstract}

Vestibular Rehabilitation (VR), a method of therapy for dizziness, aims at reestablishing body balance and also at facilitating central compensation by means of adaptation and substitution mechanisms. With technological advance, the feasibility of a device which aided in VR process took place, both for stimulating and monitoring patients. In that sense, an application called Dizziness APP was developed in order to simplify and automatize dizziness therapy process performed by the phonoaudiology professional. The aim of the present study was to report a Dizziness APP experience of usage as therapeutic strategic towards dizziness, besides comparing dizziness impact on quality of life before and after using that application. It is a descriptive, exploratory study with a qualitative approach. A subject, age 29, female gender, took participation in the present study being solely subjected to Vestibular-Ocular-Reflex (VOR) Exercises by means of vertical, horizontal and oblique optokinetic stimulation during a period of six months. The scores obtained on Dizziness Handicap Inventory (DHI), monthly, expressed by the utilization of an automatized and simplified digital process available on the Dizziness APP application, were used. Initial DHI score achieved 46 points and, upon treatment conclusion, 0 point. Using Dizziness APP as a therapeutic resource enabled the following up, monitoring and remission of dizziness symptom demonstrating the beneficial effects by means of optokinetic exercise during the Dizziness APP process of validation.

Keywords: Dizziness; Rehabilitation; Dizziness APP; Vertigo

Abbreviations: VR: Vestibular Rehabilitation; VOR: Vestibular-Ocular-Reflex; DHI: Dizziness Handicap Inventory; UNEB: University of Bahia.

\section{Introduction}

Vestibular, proprioceptive and visual systems, whose integration is responsible for balance, are processed by spinal and ocular reflexes. Cervicocollic, vestibulocollic, cervical spinal reflexes comprise the spinal reflexes. As for ocular reflexes are comprised by vestibulo-ocular, cervicalocular and optokinetic reflexes [1]. Vestibulo-ocular reflex (VOR) is responsible for stabilizing an image of a visual point, during natural head movement [2]. That movement causes retina images, from visual field, to slide. It is necessary the interaction of VOR and optokinetic and tracking systems in order to correct and stabilize these images [3].

So that body balance exists, the harmony of sensorial input from vestibular, visual and proprioceptive systems 


\section{Otolaryngology Open Access Journal}

is necessary. Alterations in any of these systems result in conflicting information. Dizziness is the most common symptom resulting from that absence of synchrony, being vertigo the main characteristic, as it presents a rotatory feature. Dizziness may also be non-rotatory and be felt as a fluctuation sensation [1]. The optokinetic system acts on continuous movement, keeping the image stable, and it depends on visual stimuli [4]. The tracking system allows image retention when a single slow movement at stable velocity goes through a visual field. The reposition of an object with a single ocular movement is called sacaddic movement and it is used by these two systems [5].

The promotion of the corrective globe movement inside the orbit, responding to head movement and thus, keeping the target in the retina during displacement is a primordial function of VOR [5]. Vertigo is frequent on young age bracket and imbalance grows proportionally to aging, being more prevalent amongst women [6], and it may also be observed during infancy and the sooner the rehabilitation, the better the therapeutical prognostic [7]. VR has proven an excellent option for balance rehabilitation. However, the results are better when the exercises are supervised [5]. The best evolutions, when exercises are used in order to rehabilitate body balance, are observed in pictures of peripheral vestibular lesions and unilateral sudden installation deficits [8].

The quality of life of a patient presenting vestibular dysfunction has shown significant improvement after VR, regardless gender and age, and has been recognized as a firstchoice treatment in many cases [9]. VR, solely by stimulation of VOR, has shown equivalent in reestablishing balance when compared to results from classic VR, with balance global training. By its easy execution and understanding, the exercises for adapting VOR may be applied to all ages [10]. Disability caused by dizziness, whether in emotional, functional or physical realms, is of great importance in social and personal contexts of an individual, regardless their etiology, once it considerably affects quality of life [11].

Dizziness APP is an application developed for Android smartphones and it is available at Play Store. It aims at improving dizziness symptoms by VOR stimulation, allowing the evolution follow-up, by the therapist, by means of filling out the Brazilian Dizziness Handicap Inventory (DHI).

The mediation of mobile devices as a proposition of entertainment, school, stimulation and health rehabilitation activities is growing in contemporary society, contributing to learning situations in distinct spaces. Its application, especially in health, allows the treatment to be aimed at stimulation or rehabilitation, extrapolating ambulatory facilities and allowing the patients to intensify their exercising. Within that context, Dizziness APP was created aiming at widening therapeutic strategies. Those strategies have been commonly used for recuperating body balance, resulting in the decrease and even the suppression of dizziness when associated with the application of protocols of eyes, head and torso, as well as the utilization of optovestibular and optokinetic stimulation.

Thus, the present study aimed at reporting a usage experience of Dizziness APP as therapy for dizziness, comparing its impact on quality of life before and after that application.

\section{Case Presentation}

It is a descriptive, exploratory study with qualitative approach approved by Research Ethics Committee of State University of Bahia, under registration number $179.799 / 2013$

\section{Otoneurological Evaluation}

The subject who took part in the present study is female, age 29, suffering from movement dizziness along with emesis for a period of more than 20 years. In 2011, she was diagnosed with labyrinthopathy, by means of videonystagmography. That test was repeated in October 2017 showing right side vestibular deficit, according to Figures $1 \& 2$.

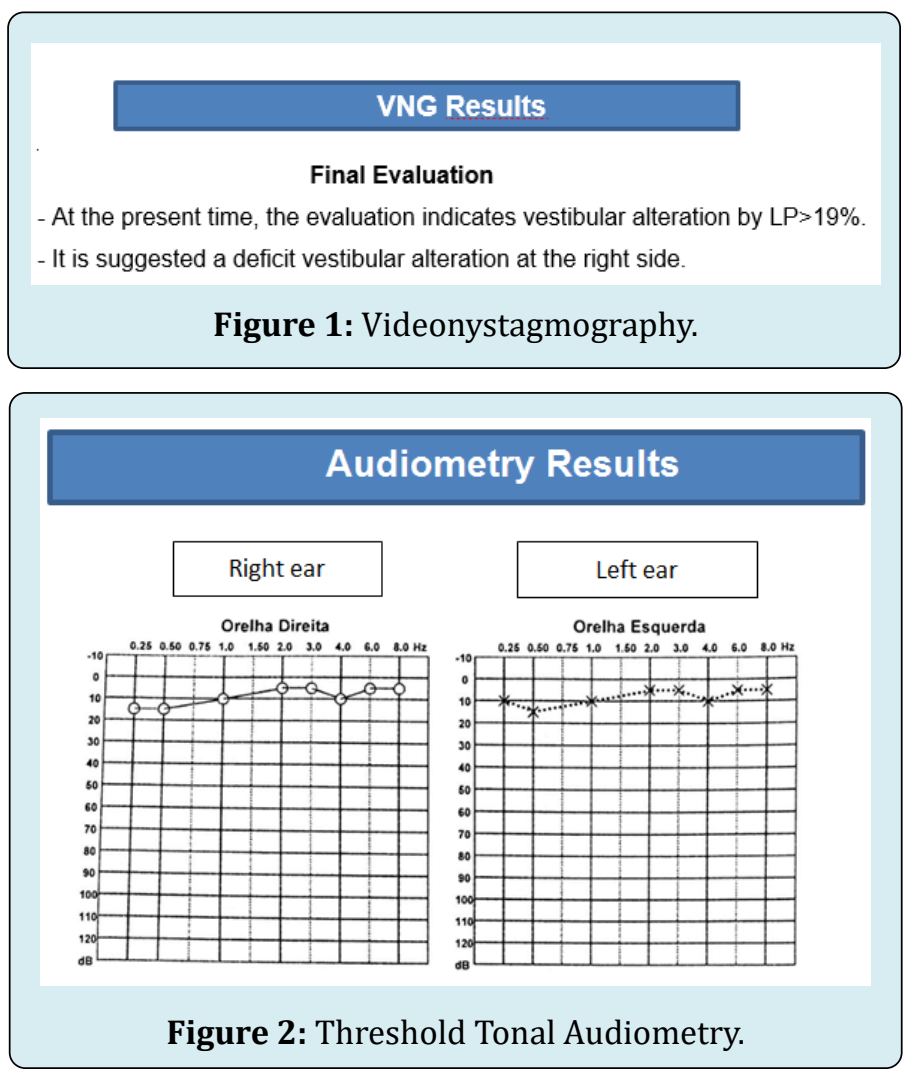




\section{Otolaryngology Open Access Journal}

After the indication of VR, the patient was subjected to therapy for vestibular rehabilitation aiming at solely performing VOR exercising with horizontal, vertical and oblique stimuli. The Brazilian Dizziness Handicap Inventory Questionnaire Castro AS, et al. [12] was filled out initially and monthly, expressed by using an automatized and simplified digital process of Dizziness APP. It is important to point out that the subject did not use any other treatments for dizziness. Not even drugs for body balance.

\section{Dizziness Handicap Inventory (DHI)}

DHI was developed and validated in the US in 1990, by Jacobson and Newman. In Brazil, DHI was translated, adapted to Brazilian culture and validated in 2007, by Castro AS, et al. [12]. It is a questionnaire for evaluation of patients' quality of life when experiencing dizziness. Questions referring to emotional aspects are related to psychological symptoms associated with dizziness, such as fear, frustrations, shame, incapacitation feelings, among others. Among functional aspects, interference in performing body, head and eyes movements when doing domestic, professional, social and leisure activities. As for physical aspects, they investigate the influence of such movements on dizziness increase or onset [12].

DHI is an instrument composed by 25 questions aimed at evaluating self-perception of incapacitating effects imposed by dizziness on adults and senior subjects, organized in three subscales: Functional (nine items), emotional (nine items) and physical (seven items). The gradation of the answer goes from 0 ("no") to 4 ("yes"), with an intermediate value 2 ("sometimes") also existing. The maximum score for the physical scale is 28 points; for the emotional and functional subscale is 36 points each, totaling 100 points. DHI also enables informing about dizziness incapacitation extent which varies accordingly to total scale scores and those of the subscales [13]. Considering the total score, the incapacitation degree may be light ( 0 to 60 points), moderate (30 to 60 points) or severe (above 60 points).

Considering the emotional and functional subscales, incapacitation degree may be inexistent ( 0 to 14 points), revealing moderate deficiency (15 to 24 points) or severe deficiency (above 25 points). As for the physical subscale, incapacitation degree may be inexistent ( 0 to 9 points), revealing moderate deficiency (10 to 16 points) or severe deficiency (above 17 points).

\section{Dizziness App}

Dizziness APP is pioneering dizziness therapy application and it was conceived for VOR stimulation. It was developed by scholars from the Information Technology Course along with a teacher in Phonoaudiology at State University of Bahia (UNEB).

Among the APP various functions, its database will allow the phonoaudiologist the follow-up and monitoring of the exercises, enabling them to keep track of the evolution by means of the system's efficiency. The Application allows exercising at home which is more convenient. Besides contributing to elaborating daily, weekly and monthly reports, Dizziness APP allows producing statistics, so we know the degree of interactivity and productivity of the patient, which is a satisfactory factor, serving as a parameter to modelling the methodology applied.

Dizziness APP offers the possibility of measuring incapacity degree while responding to the symptoms perceived by the patient during treatment. Upon each access, the patient is inquired about answering DHI and the answer is registered so that it emits a score ranking according to incapacity degree related to total score and physical, emotional and functional subscales (Figure 3).

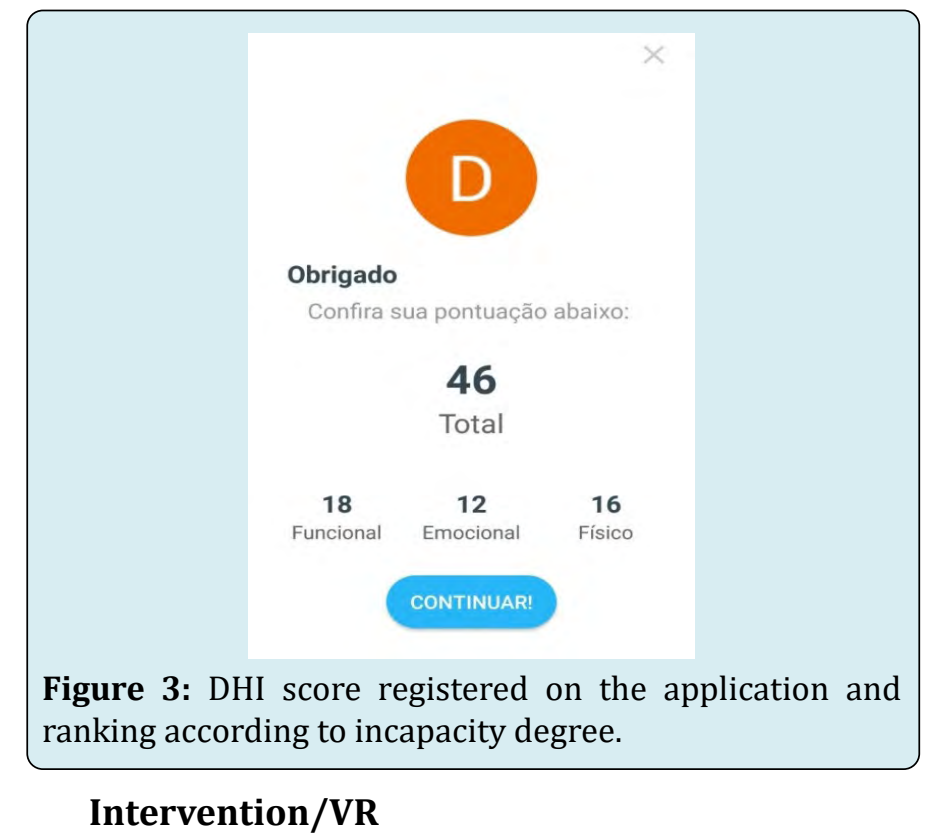

The patient was subjected to optokinetic stimulation training in three planes of spatial orientation, namely: horizontal, vertical and finally, oblique plane for VOR stimulation. The patient was to look at the black stripes of the optokinetic drum, according to Figure 4 . The sessions were performed daily. After ten sessions, a change of the plan to be stimulated was required. Initially at the vertical position (duration of 15 minutes of clockwise rotation and then 15 minutes anti-clockwise rotation). Subsequently, at the horizontal position (15 minutes downwards and 15 minutes upwards) and, lastly, at the diagonal position (15 minutes 
superior-left to inferior-right and 15 minutes superior right to inferior-left) according to Figure 4 . After 30 sessions, the stimulation by the initial plane of orientation was restarted. Each session was registered on the application as exemplified in Figure 5.
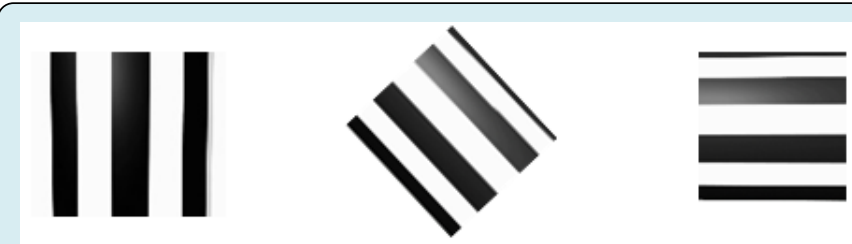

Figure 4: Position of the striped drum for optokinetic stimulus.

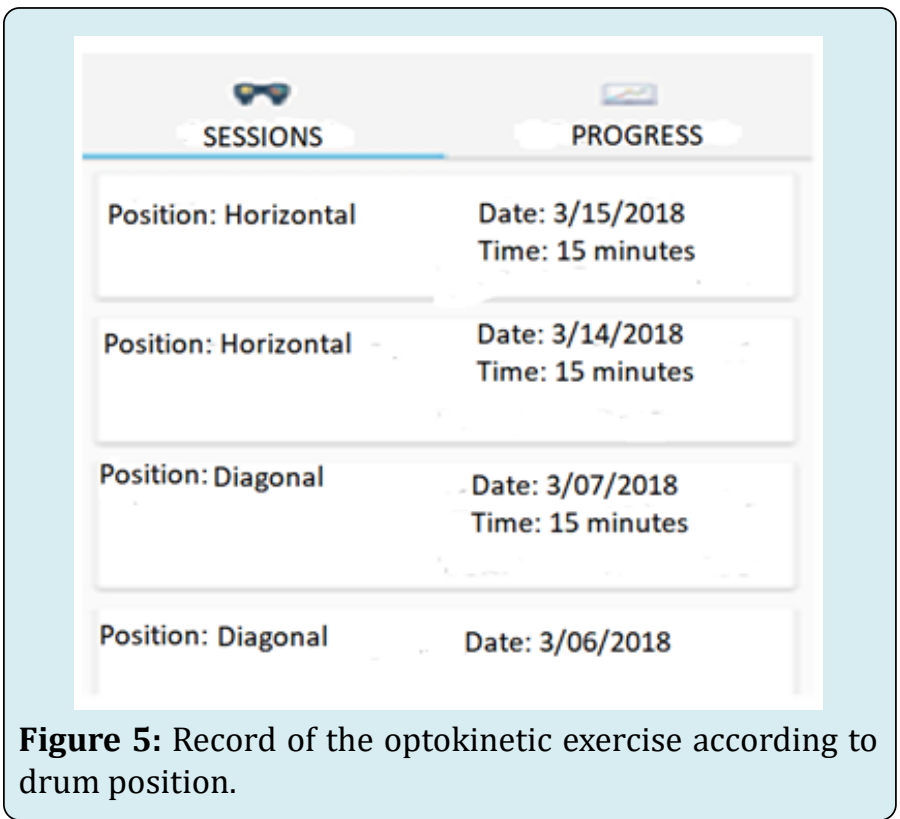

Both Dizziness APP and DHI Questionnaire are selfexplanatory, which renders training for sessions execution unnecessary. Prior to initiating each session, the application guides users to place the mobile (smartphone) adjusted to their line of sight.

Data analysis was performed by comparing DHI, initial, subsequent and post-therapy.

\section{Results}

During therapeutic process, symptoms such as emesis, dizziness, migraine and pain in the eyes were observed, after stimulation. The episodes decreased throughout a period of six months, being the last month uneventful in terms of symptoms, as described at Table 1.

\begin{tabular}{|c|c|c|c|c|c|c|}
\hline & $\begin{array}{c}\text { 17- } \\
\text { Oct }\end{array}$ & $\begin{array}{c}\mathbf{1 7 -} \\
\text { Nov }\end{array}$ & $\begin{array}{c}\mathbf{1 7 -} \\
\text { Dec }\end{array}$ & $\begin{array}{c}\mathbf{1 8 -} \\
\text { Jan }\end{array}$ & $\begin{array}{c}\mathbf{1 8 -} \\
\text { Feb }\end{array}$ & $\begin{array}{c}\mathbf{1 8 -} \\
\text { Mar }\end{array}$ \\
\hline Emesis & 3 & 2 & 1 & 1 & 0 & 0 \\
\hline Dizziness & 2 & 4 & 0 & 0 & 0 & 0 \\
\hline Migraine & 1 & 2 & 1 & 0 & 1 & 0 \\
\hline $\begin{array}{c}\text { Pain in } \\
\text { the eyes }\end{array}$ & 1 & 0 & 1 & 0 & 0 & 0 \\
\hline
\end{tabular}

Table 1: Symptoms reported on Dizziness APP during optokinetic exercises.

Functional and emotional domains obtained the best results, when comparing initial and final DHI. However, physical aspect had a significative reduction of $75 \%$ in dizziness onset and increase when performing body, head and eyes movements (Graphic 1).

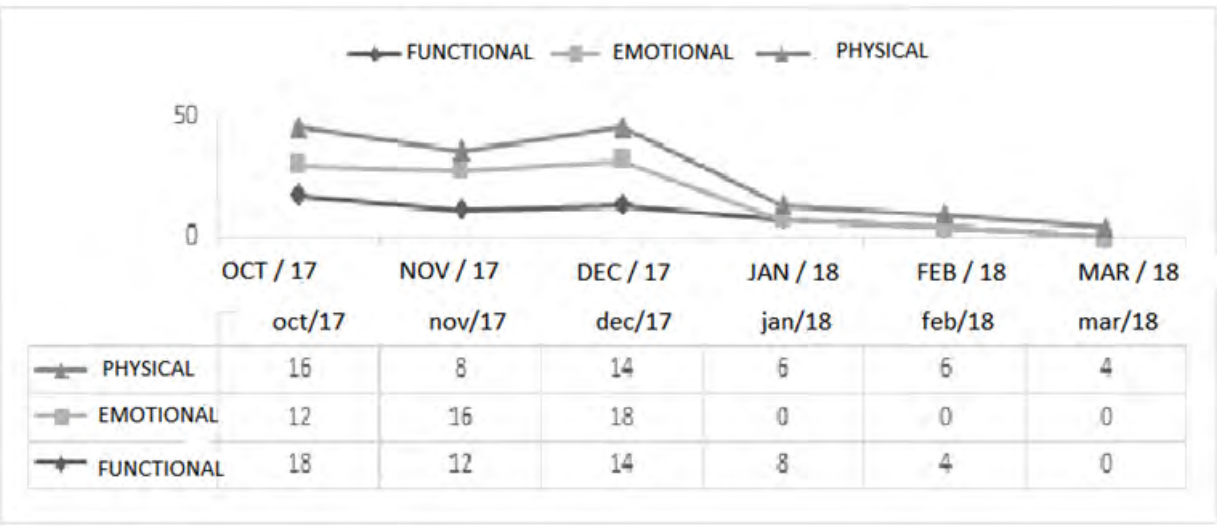

Graphic 1: Graphic representation of scores pertaining to physical, emotional and functional aspects.

DHI initial score, measured in October, was 46 points; in November, 34 points and, in December, 44 points. In January, the score was equal to 10 points, decreasing to 6 in February and, finally, in March, after 6 months of treatment, it fell back to 4 points (Figure 6). 


\section{Otolaryngology Open Access Journal}

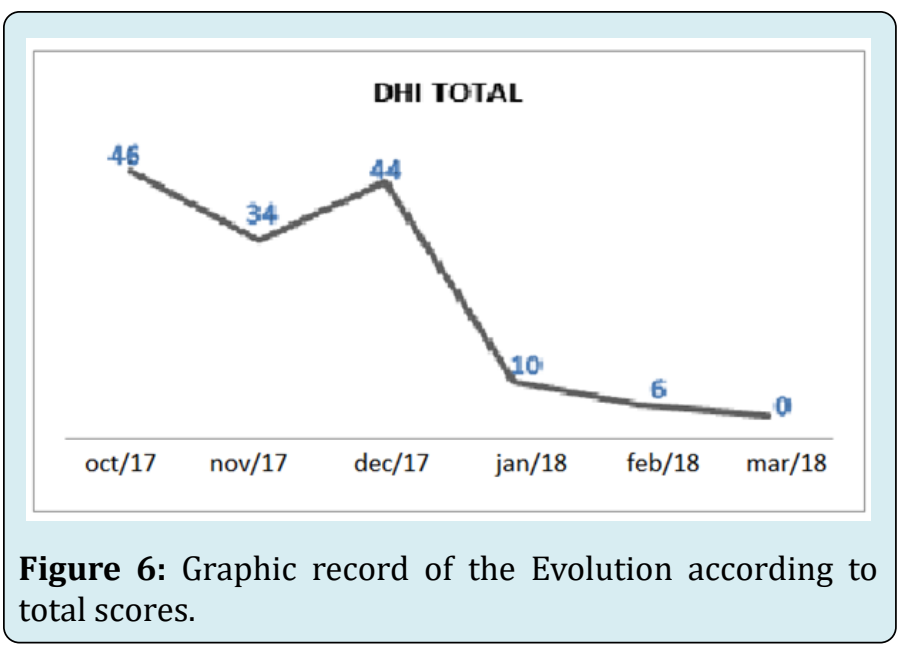

\section{Argumentation}

As observed by Manso A, et al. [14], the functional aspect obtained the highest score for initial DHI, compared with other aspects, thus demonstrating dizziness impact on exercising and performance of daily activities, whether domestic, professional, social or leisure activities. On VR, the exercises tend to improve vestibulo-visual interaction during cephalic movement while augmenting postural stability in the conditions which produce conflict in sensorial information [15]. In view of this, VR has been proven an excellent therapeutical resource in recovering body balance [5]. According to Simoceli L, et al. [10], when vestibular rehabilitation is performed exclusively by means of VOR stimulation, ithas demonstrated that balance reestablishment was equivalent if compared to the conventional VR results. Such finding corroborates those found at the present case study, being that strategy an efficient one for treating dizziness, once VOR stimulation was performed.

Manso A, et al. [14] described stimulation by digital images as an efficient ally in dizziness treatment, mainly regarding peripheral vestibulopathies, as a new option for the rehabilitators. Yet, they stressed the need of studies which include visual stimulation with the utilization of digital images, in rehabilitating balance.

\section{Conclusion}

Utilizing Dizziness APP as therapeutical resource enabled the following up, monitoring and remission of dizziness symptom demonstrating the beneficial effects of that tool, by means of optokinetic training during the validation process. In that sense, the developed tool led to dizziness symptom remission, besides informing the incapacity degree, interactivity, productivity and effectiveness of the treatment, that is, if the same was satisfactory or not. Furthermore, the present study intends to fill a gap related to the creation of a digital tool applied to health field relating researches to games development and one that aims at aggregating researchers, developers and those who take interest in the productive interface between health and digital games, understood in their physiological, psychological, social and collective dimensions.

The utilization of Dizziness APP for dizziness therapy promoted improvement in body balance, mainly in the symptom vertigo, migraine, emesis and eyes pain. However, new studies are needed, once it is not possible to generalize the results, because it is a study performed with one patient in a situation where clinical evidence was robust. Therefore, we suggest new investigations on Dizziness APP utilization in clinical trials with a greater number of subjects.

\section{References}

1. Ganança FF, Manoel EM, Duarte JA (2014) Clinical treatment of the vertiginous patient. In: Maia FCZ, et al. (Eds.), Current Otoneurology. Rio de Janeiro: Revinter, pp: 461-478.

2. Maia FCZ (2015) Balance Rehabilitation. Practical Elements in Otoneurogy. Rio de Janeiro: Revinter, pp: 143-154.

3. Gonçalves DU, Ganança FF, Bottino MA, Greters ME, Ganança MM (2014) Vestibular rehabilitation. Clinical otoneurology. Rio de Janeiro: Revinter, pp: 185-194.

4. Maia FCZ, Albernaz PLM, Carmona S (2014) Anatomical principles that govern balance. Current Otoneurology. Rio de Janeiro: Revinter, pp: 1-24.

5. Gonçalves DU, Ganança FF, Bottino MA, Greters ME, Ganança MM (2014) Vestibular anatomophysiology. Clinical otoneurology. Rio de Janeiro: Revinter, pp: 3-24.

6. Bittar RSM, Oiticica J, Bottino MA, Ganança FF, Dimitriv $R$ (2013) Population epidemiological study of the prevalence of dizziness in the city of São Paulo. Braz J Otorhinolaryngol 79(6): 688-698.

7. Novalo ES, Goffi Gomez MVS, Medeiros IRT, Pedalini MEB, Santos RMR (2007) Vestibular disorders in childhood: study of spatial disorders. Rev CEFAC São Paulo 9(4): 519-531.

8. Garcia FV, Borges NF, Benzinho TA (2014) Vestibular reeducation. In: Maia FCZ, Albernaz, PLM, Carmona S, Current Otoneurology. Rio de Janeiro: Revinter, pp: 501534.

9. Romero ACL, Hayashi MSY, Kishi MS, Cardoso ACV, Frizzo ACF (2015) Dizziness Handicap Inventory-in a 


\section{Otolaryngology Open Access Journal}

group of patients undergoing personalized vestibular rehabilitation. Rev CEFAC 17 (3): 792-800.

10. Simoceli L, Bittar RSM, Sznifer J (2008) Effectiveness of the vestibulo-ocular reflex adaptation exercises on the postural stability of the elderly. Arq Int Otorrinolaringol Sao Paulo 12(2): 183-188.

11. Ayala LLM, Velasquez MIC (2014) Evaluation of patients with vertigo using the vertigo disability questionnaire (DHI). An Otorhinolaryngol mex México 59(1): 59-65.

12. Castro AS, Gazzola MJ, Natour J, Gananca FF (2007) Brazilian version of the Dizziness Handicap Inventory.
Pro Fono R Atual Scient 19(1): 97-104.

13. Jacobson GP, Newman CW (1990) The development of the dizziness handicap inventory. Arch Otolaryngol Head Neck 116(4): 424-427.

14. Manso A, GananCa MM, Caovilla HH (2016) Vestibular rehabilitation with visual stimuli in peripheral vestibular disorders. Braz J Otorhinolaryngol 82(2): 232-241.

15. Ricci NA, Aratani MA, Dona F, Macedo C, Caovilla HH, et al. (2010) Systematic Review of the Effects of Vestibular Rehabilitation on Middle-Aged and Elderly Adults. Rev Bras Fisioter 14(5): 361-371. 